\title{
PHYTOPHARMACEUTICAL POTENTIALS OF PROSOPIS LAEVIGATA, SYMPLOCOS COCHINCHINENSIS AND NYMPHAEA ALBA: A REVIEW
}

\author{
DIKSHA MATTA, HARSHIT NANDA, GAYATHRI MAHALINGAM* \\ Department of Biotechnology, School of Bio Sciences and Technology, VIT University, Vellore - 632 014, Tamil Nadu, India. \\ Email: gayathrigopinath@vit.ac.in
}

Received: 29 May 2017, Revised and Accepted: 12 July 2017

\begin{abstract}
Medicinal plants are used from a very long interval of time for treatment of several diseases. In this review, we present detailed information about the diversified medicinal properties of three different plants, namely, Prosopis laevigata, Symplocos cochinchinensis, and Nymphaea alba. The different medicinal properties found in these three unexplored plants can have industrial applications in the treatment of peculiar diseases such as heart attacks and hypercholestriamia. The typical medicinal properties found in these plant's antioxidant, antibacterial, and antimicrobial activity, which suggests that all these plants can be used in drug design and modeling at commercial level. The unique properties of $P$. laevigata include anti-biofilm and anti-corrosion activities. The exclusive properties found in S. cochinchinensis include anti-snake venom activity and anticancer activity. The rare properties of $N$. alba include uterotonic and anxiolytic activities. Combining all these activities, we compare all the properties in these plants and hence conclude with the future therapeutic applications in drug design of these plants.
\end{abstract}

Keywords: Medicinal, Phytochemical, Anti-biofilm, Applications, Industry, Antioxidant, Analgesic, Ureotonic.

(C) 2017 The Authors. Published by Innovare Academic Sciences Pvt Ltd. This is an open access article under the CC BY license (http://creativecommons. org/licenses/by/4. 0/) DOI: http://dx.doi.org/10.22159/ajpcr.2017.v10i10.20316

\section{INTRODUCTION}

Medicinal plants are used as raw materials for traditional purposes [1]. Their effectiveness, lack of medicinal alterations, reduction in cost and availability are the major reasons behind their use from ancient times [2]. Medicinal plants serve as an Ayurveda remedy in the medicinal systems from a very long time [3]. They are the best source for a variety of drugs and have been used in substantial quantities in drugs used for the treatment of burning diseases [4]. Medicinal plants contain several bioactive compounds used medicinally. Some of them include tannins, alkaloids, carbohydrates, terpenoids, steroids, and phenols.

Medicinal plants contain a variety of secondary metabolites that have been used as a functional food source for higher nutritive value [5]. They are used as therapeutic agents from ancient times to treat diseases (Graph 1) [6]. The different parts such as roots, stems, and leaves are the best strategy which is used toward conservation of bioresources and bioprospecting medicinal plants [7]. The different parts are used to treat emerging diseases such as diabetes, skin diseases, food poisoning, and upper respiratory disorders [8]. Bryophytes as medicinal species acts for soil erosion control, aquatic bioindicators, mass gardening, and treatment of waste materials [9].

Prosopis laevigata, Symplocos cochinchinensis, and Nymphaea alba belong to same class Magnoliopsida. Magnoliopsida class consists of 1,70,000 species of angiosperms [10]. It's a class which includes flowering plants and dicots. Dicots are varied in habitat, and most of the species are less woody, epiphytes, parasites, annuals, biennials, saprotrophs, vines, and aquatics. They are mostly derived from radicles. The class includes some major authentic flowering plants as tinea, water lily, legumes, and buttercup, rose, bluebell, and aster families.

\section{P. laevigata}

P. laevigata (common mesquite) is a species of the Fabaceae family. The plant is native to Mexico and United States in Northern America and Argentina, Bolivia and Peru in Southern America. In Mexico, it is found in central highlands, lowlands of southern Tamaulipas and in parts of Oaxaca, Morelos and Chiapas. It has also been spotted in the Middle East [11].
The plant has cardioprotection potential [12] and is quite useful in the treatment of heart diseases. The plant also has exhibited anticorrosion [13] and anti-biofilm activity [14], which are used for medicinal purposes. This plant has also been used as windbreaks. The gum of the plant, when mixed in water, is used to treat throat infections and dysentery [15]. The shoots and juice of $P$. laevigata have been found to provide relief against eye inflammations.

\section{S. cochinchinensis}

$S$. cochinchinensis is an evergreen tree. It can grow up to a height of $35 \mathrm{~m}$. The tree acts as a source of food, dye, tannins, alkaloids, and wood. It is typically found in different parts of China, Japan, India, Sri Lanka, Myanmar, Malaysia, and Fiji.

The different varieties of this plant are consumed and are used in various forms. The variety sessilifolia is used as a food supplement in the form of lalab. The bark of the tree is found to be rich in tannins and aluminum metal. The leaves of the plant are simple and alternate. The apex of the leaves is acuminate, base acute and margin is serrate. Inflorescence is axillary, and flowers are spike and found to be white in color. The fruit of this plant is of drupe type, and the seeds of this plant are of ampliform type [16].

\section{N. alba}

N. alba commonly known as a water lily is a part of the Nymphaeaceae family. A prominent plant in traditional Indian medicine has been long used to treat gastrointestinal, genital, and bronchial conditions.

It is a rich source of flavonoids, phenols, and fatty acids. Studies show that flowers, leaves, and rhizome of $N$. alba have various medicinal properties. It includes anti-inflammatory, analgesic, astringent, anticancer, and antioxidant property [17-22].

\section{GENERAL DESCRIPTION OF MEDICINAL PLANTS}

\section{P. laevigata}

- Lifestyle: P. laevigata generally occurs as a tree or shrub. It can sometimes grow up to a height of 10-13 m. It has a thick trunk with a wide cup 
- Leaves: The leaves of $P$. laevigata are sessile containing an obtuse base. Its apex has petioles with 2-4 pairs of pinnae

- Flowers: The flowers of P. laevigata are mostly sessile with a calyx of $2 \mathrm{~mm}$. They are smooth and hairless and have sharp petals

- Fruits: The fruits occur as linear pod or leguminous in nature with 8-25 $\mathrm{cm}$ long by $10-20 \mathrm{~mm}$ wide

- Seeds: The seeds of this plant are generally compressed, shrunken in shape and usually 10-12 mm long (Figs. 1 and 2).

\section{S. cochinchinensis}

- Range: S. cochinchinensis is found in East Asia, Japan, India, Thailand, Malaysia, and Fiji

- Habitat: The plant is mostly found in dipterocarp forests, slopes of hills, brown soil, and evergreen forests

- Height: S. cochinchinensis can grow up to $20 \mathrm{~m}$ in height

- Cultivation status: The cultivation status of this plant is of wild type. Commonly found in the wilds

- Edible uses: The species sessilifolia is used as lalab and hence acts as a food source [23] (Fig. 3).

\section{N. alba}

- Flower: The flowers of this plant are regular, bowl shaped, and anthers are yellow in color

- Leaves: The length of leaves is $10-25 \mathrm{~cm}$, oval shaped and color of this plant ranges from dark green above and reddish brown below

- Fruit: The fruit of the plant is of fleshy berry and capsule in nature

- Habitat: The plant is commonly found in ponds, lakes, and rivers

- Flowering time: The flowering time is from June to August [24] (Fig. 4).

\section{Phytochemistry}

Phytochemistry refers to the study of different phytochemicals, which are the various chemicals derived from medicinal plants. We have discussed the various phytochemicals present in P. laevigata, S. cochinchinensis and N. alba in this section.

\section{P. laevigata}

The most important bioactive substances found in P. laevigata are alkaloids, flavonoids, terpenes, and phenolic compounds are the most important bioactive substances found in Prosopis spp. Terpenes are basically used as insecticides to remove harmful effect of pests and growth of insects on different plants. The two different alkaloids present in Prosopis spp. are proserpine and prosopinine. Alkaloids of Prosopis spp. are used as analgesics and antimalarial agents. The tannins present contain $7-22 \%$ and $0.5-3.9 \%$ of flavonoids [25]. The Prosopis spp. examined was found to contain high density and levels of non-protein amino acids, pipecolic acid, 4-hydroxypipecolic acid, and proline amino acid [26] (Fig. 5).

\section{S. cochinchinensis}

The powdered form of $S$. cochinchinensis is found to have alkaloids, cardiac, anthraquinone, saponin, coumarin type of glycosides, terpenoids, carbohydrates, proteins, steroids, flavonoids, phenolic compounds, lignin, and the methanolic extract of the plant resulted positive in saponins also [27].

\section{N. alba}

The flowers of $N$. alba have flavonoids. The flowers and rhizome of $N$. alba were found to be rich in phenols such as ellagic and gallic acid. It also contains essential fatty acids that have alimental value. It was identified a rich source of $\beta$-sitosterol and a high antioxidant property [28].

\section{MEDICINAL PROPERTIES}

\section{P. laevigata}

\section{Antioxidant capacity}

$P$. laevigata helps in nitrogen fixation in the soil and promote the elongation of herbs and shrubs. The antioxidant capacity of $P$. laevigata was performed by 2, 2-diphenyl-1-picrylhydrazyl (DPPH) radial

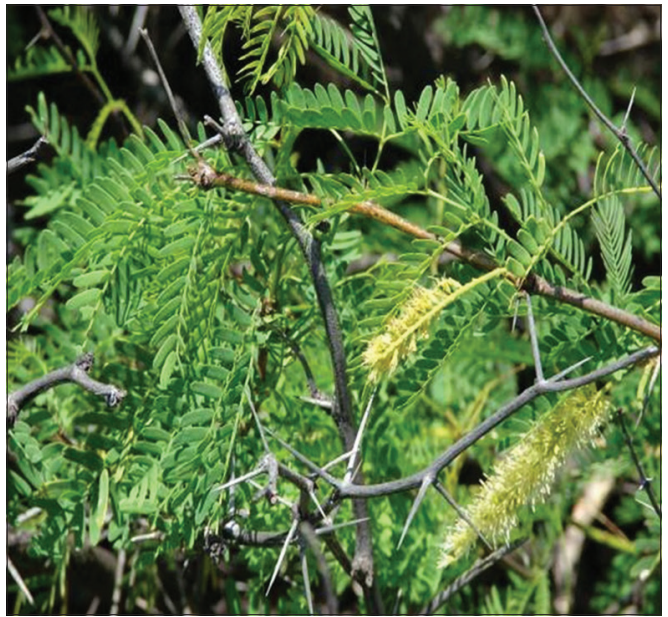

Fig. 1: Leaves of Prosopis laevigata

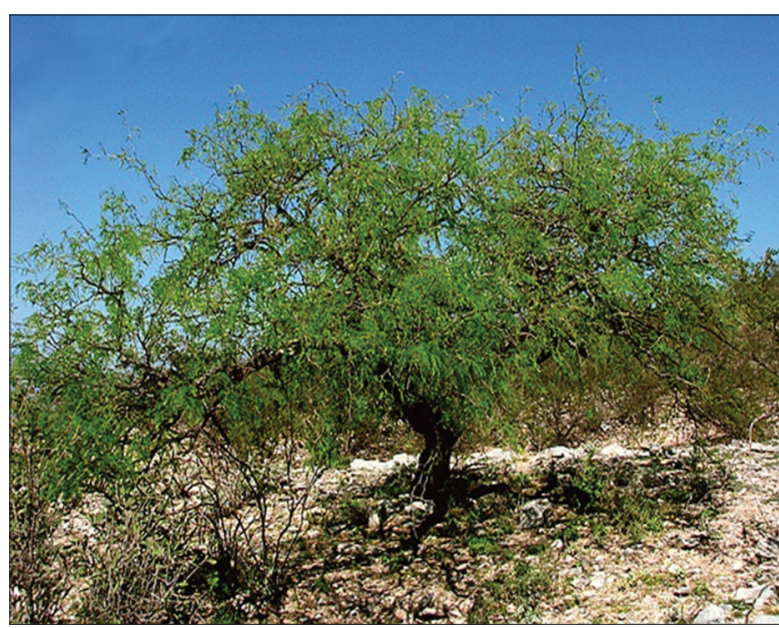

Fig. 2: Prosopis laevigata Source: iNaturalist.com

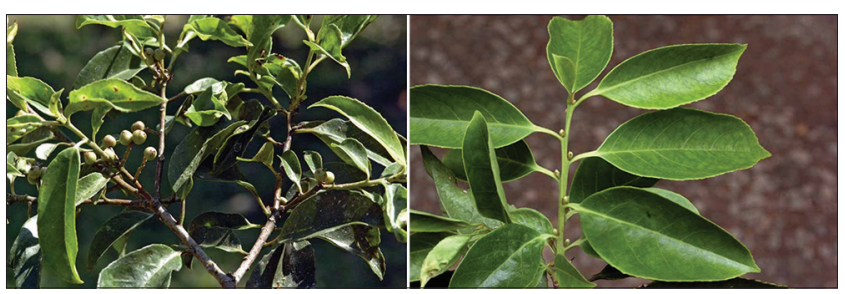

Fig. 3: Leaves of Symplocos cochinchinensis. Source: biotik.org
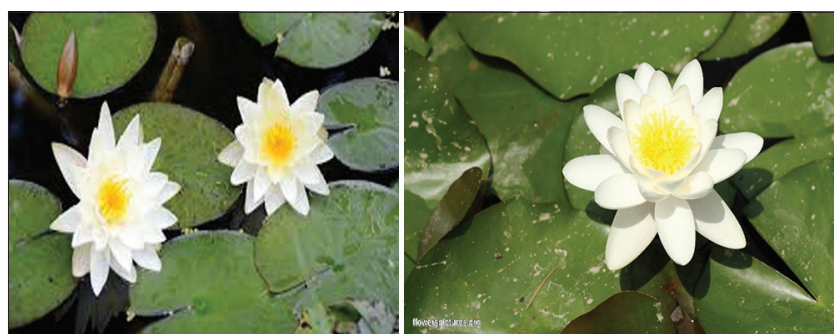

Fig. 4: Flowers and Leaves of Nymphaea alba plant. Source: uniprot.org

scavenging activity and maximum percentage of inhibition. The results were verified by hydroxyl scavenging methods. The scavenging activity 


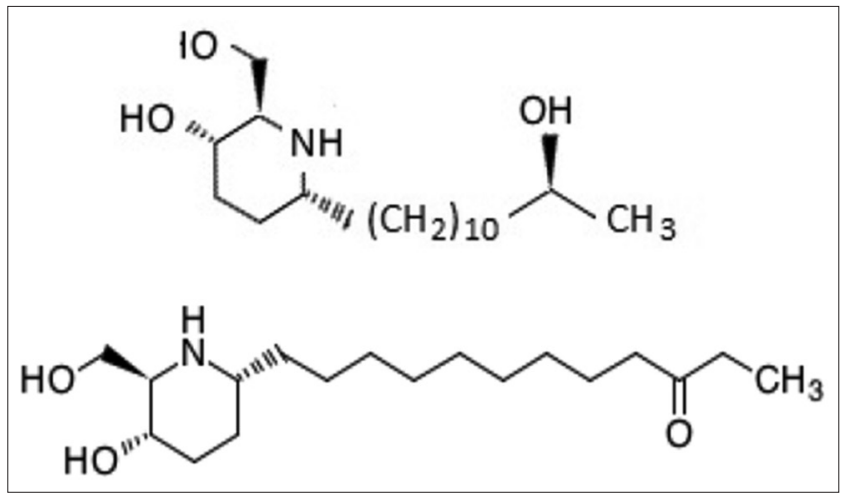

Fig. 5: Chemical structures of alkaloids found in Prosopis laevigata plant [13]

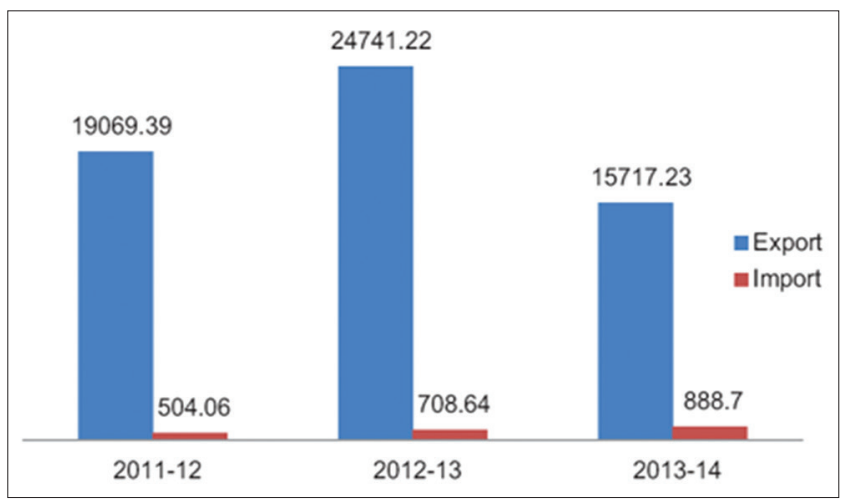

Graph 1: Number of medicinal plants used within the previous years in AYUSH (Ayurveda, Yogic, Unani, Siddha, and Homeopathy)

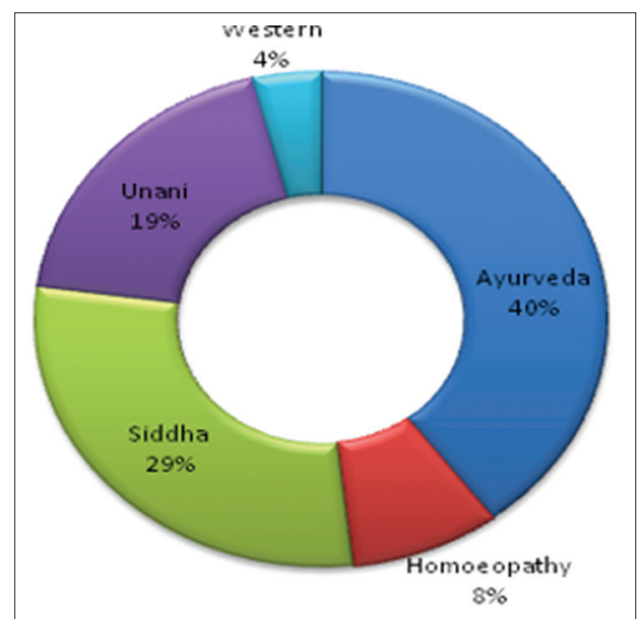

Graph 2: Percentage use of plant species under different system of medicines (NMPB, 2008)

showed that polar extracts obtained from P. laevigata leaves, thus possess antioxidant capacity to slow down the peroxidation process or to decrease the mechanism of damaging of cells [29].

\section{Cardioprotective potential}

The cardioprotective potential of $P$. laevigata is determined as it inhibits low density lipoprotein oxidation and angiotensin converting enzyme (ACE) inhibition. Flavonoids existing in P. laevigata leaves have functional properties of controlling the blood pressure, for example, epicatechin gallate and their glycosides. Thus, polar extracts obtained from this plant possess antioxidant, anti-hypersensitive, and cardioprotection effect [12].

\section{Antibacterial activity}

The extract of bark and leaves of P. laevigatain methanol was found to show inhibitory activity against pathogenic bacteria K. pneumoniae, E. faecalis, and S. aureus. Zone inhibition activity followed by minimum inhibitory tests and minimum bactericidal concentration tests were evaluated to give Laevigata antibacterial activity. Previously, other species of Prosopis such as Prosopis spp and P.juliflora have shown similar properties against microorganisms. Laevigata strong potential antibacterial activity is possibly a result of the alkaloid, flavonoids, coumarins, and tannins [12]. This property can be utilized in pharmaceutical applications.

\section{Anti-biofilm activity}

Colonies of microorganisms often adhere together and to the surface to form a sticky layer called as a biofilm. It is a causative agent of many infections. The plant extract of $P$. laevigata from the minimum bacterial concentration showed anti-biofilm activity with considerable reduction against specific biofilm formation of E.coli and S. aureus. Anti-biofilm properties are a result of phytochemical properties like antibacterial property [14]. However, the full potential of anti-biofilm activity in $P$. laevigata is yet to be explored.

\section{Anthelmintic effect for treatment of nematodiasis}

P. laevigata is traditionally been used as a folk medicine and a natural remedy for treatment of gastrointestinal disorders. For verification of anthelmintic property the study was mainly focused on gerbils of sheep. The biologically active compounds usage with nematicidal property has been a topic of massive importance. The administration of P. laevigata n-hexane extract is commercially used for $H$. contortus infected gerbils $[30,31]$.

\section{Anti-corrosion activity}

$P$. laevigata acts as a corrosion inhibitor for aluminum metal in the presence of hydrogen sulfide solution. The anti-corrosion activity of the plant is tested by weight loss by acting as a cathodic inhibitor and electrochemical spectroscopy techniques. The effectiveness of $P$. laevigata increases with an increase in concentration of plant extract and generally it decreases with increase of temperature. The plant undergoes the process of adsorption on the metal surface and forms a film between the metal surface and the surrounding corrosive environment. This is the major principle of how the plant slows down and decelerates the process of corrosion on metal surface. The inhibitory effect of corrosion seen is mostly due to the presence of proserpine and prosopinine that form a shield by reaction with aluminum (III) ions and decreases the corrosion reaction barrier [32].

\section{Antifungal activity}

The preparation of extract of $P$. laevigata was done using the Soxhlet apparatus. The extraction results show that there is a high resistance activity against fungi and other disease causing microbes in soil. The phytochemical analysis of sawdust of P. laevigata resulted in the presence of high concentration of phenol and flavonoids bioactive compounds. The wood extracts from P. laevigata have a high natural potential for wood protection and durability. The durability of wood of $P$. laevigata, effect of its extract inhibits the growth of wood decaying fungi present in soil [33].

\section{S. cochinchinensis}

\section{Antioxidant property}

S. cochinchinensis is traditionally been used as an Ayurvedic medicine to treat several inimical disorders such as leprosy, diarrhea, dysentery, and inflammation. Polyphenolic compounds found in S. cochinchinensis are characterized to have antioxidant property due to the enormous amount of phenolic compounds present in it. Reducing capacity of a compound is an indicator of antioxidant property. Reducing capacity of 
a plant sample is opposite to its oxidizing capacity. S. cochinchinensis methanolic extract is investigated to have antioxidant property, thus helpful in preventing various oxidative stress related diseases [34].

\section{Antidiabetic property}

The hydroethanol extract of $S$. cochinchinensis is found to have antidiabetic property. Diabetes is a syndrome which is related to the unsubstantial production of insulin or impaired response to insulin. The various oxidative stress markers of the extract such as glutathione and malondialdehyde are found to exhibit antidiabetic activity. Oxidative stresses and diabetic complications in the human body increase the development of hyperglycemia. S. cochinchinensis exerts beneficial effects on liver, kidney, and pancreas against hyperglycemia. Thus, the hydroethanol extract is found to have antidiabetic properties [35].

\section{Anti-inflammatory activity}

Inflammatory response involves a series of complex reactions such as enzyme activation, mediator release, redness, swelling, and pain. The methanolic extracts of $S$. cochinchinensis exhibit membrane stability by inhibiting hypotonicity induced lysis of human erythrocyte membrane. It thus exhibits anti-inflammatory process by inhibiting edema. The anti-inflammatory response also inhibits lysosomal enzymes action causing inhibition [36].

\section{Hepatoprotective role}

Free radical autooxidation process of membrane lipids lead to necrosis process and are a very crucial process in pathological conditions. $S$. cochinchinensis is used to treat liver disorders. On successful administration of methanolic extracts of leaves of $S$. cochinchinensis leads to a decrease in levels of enzymes causing liver related problems to a normal level. Rats treated with this extract showed decrease in the levels of lipid peroxidase enzymes [37].

\section{Anti-snake venom activity}

The methanolic extract of $S$. cochinchinensis is found to have unique anti-snake venom activity. The snake venom acts on the neuromuscular junction by the release of acetylcholine neurotransmitter. The extract thus interferes with this process of binding by the action of neurotoxic substances present in the venom at acetylcholine receptor sites [38]

\section{Anticancer activity}

Chemopreservation is a technique where by the use of synthetic or natural agents stop the development of cancer [39]. The anticancer activity was investigated using a methanolic extract of S. cochinchinensis using Dalton's ascetic lymphoma cell lines. An increase in the lifespan of different animals was observed by treatment of this extract and a sudden decrease in the tumor volume, tumor cell count, and hematological pattern was notified [40].

\section{Antimicrobial activity}

The methanolic extract of leaves, root, and stem barks of S. cochinchinensis shows antimicrobial activity. The crude extracts of the plant show a broad spectrum of antibacterial property as well. Antimicrobial activity of this plant is yet to be explored in detail [41].

\section{N. alba}

\section{Antibacterial activity}

Extracts of $N$. alba were tested for antibacterial activity in a study. The results showed an inhibition diameter of $20.2 \mathrm{~mm}$ when the ethanolic extract was tested against the Gram-negative bacteria E. cloacae. Methanolic extract against the same bacterium resulted in the inhibition diameter of $20 \mathrm{~mm}$ [39].

\section{Anticarcinogenic property}

$N$. alba is a common medicinal plant in indigenous Indian medicine practices. It is often used as fomentation to inflammation and ulcers. It possesses substantial anti-tumor activity. The methanolic extract gave $100 \%$ inhibition using a potato disc method with camptothecin and water as positive and negative controls, respectively. The study reports that $N$. alba reduced the enhanced enzyme levels induced by potassium bromate (KBrO3), a common food additive which promotes tumor promotion response and oxidative stress in Wistar rats.

One of the main active constituents of $N$. alba is ellagic acid, a carcinopreventive agent. It has a tumor inhibitory activity for small intestine, lung, liver, and other target organ cancers. Another constituent quercetin can regulate biochemical activities such as change in protein kinase $\mathrm{C}$ activity, interacts with calmodulin, and interferes with tumor promotion. Apigenin is present in N. alba is found to have some anticancer effect. It also has antiallergic, antibacterial, antihistaminic, anti-inflammatory, antioxidant, and antimutagenic effects $[18,42,43]$.

\section{Accumulator of chromium}

N. alba was found to be a potential accumulator of chromium, a heavy metal which a major pollutant of the soil and water bodies. The leaves and rhizomes of $N$. alba accumulated maximum concentrations and the plant could exhibit up to $1 \mu \mathrm{M}$ Chromium level tolerance [44].

\section{ACE activity}

Inhibitors of ACE plays a crucial role in treating hypertension. N. alba showed moderate ACE inhibition with about $66.3 \%$ inhibition at $330 \mu \mathrm{g} / \mathrm{ml}[45]$.

\section{Uterotonic properties}

Ethanolic extracts of $N$. alba have been found to have properties like mammalian oxytocin. Study shows that it possess active compounds which can trigger the receptor response of endometrial and myometrial lining of uterus. It was able to induce a dose-related increase in force of contraction of rat uterus when tested against like antagonists such as salbutamol and atropine [46].

\section{Antidiarrheal activity}

In vivo studies of $N$. alba showed antidiarrheal activity by yielding significant results in inhibiting gastrointestinal motility. In this study, diarrhea was induced in rats by castor oil that leads to an increase of intestinal contents by stopping the reabsorption of water. An ethanolic extract of the rhizome decreased the rate of intestinal transit, and there was a reduction in the volume of feces. It concluded that in future $N$. alba might be a potential source of antidiarrheal drug [47].

\section{Anti-inflammatory activity and acute toxicity}

Anti-inflammatory activity in ethanolic extracts of $N$. alba was found using carrageenan induced rat paw edema. The results concluded that it does not induce anti-inflammatory activity. The ethanolic extract produced no apparent toxicity or sign of death when induced with doses from 100 to $2000 \mathrm{mg} / \mathrm{kg}$ [47].

\section{Analgesic activity}

Acetic acid-induced writhing test and formalin-induced paw licking method were conducted on the extract of $N$. alba. The plant extract was found more potent than the standard drug when given at $600 \mathrm{mg} / \mathrm{kg}$ in both the cases [47].

\section{Antioxidant activity}

Antioxidant activity was tested $\mathrm{DPPH}, \mathrm{O}_{2}$, nitric oxide, and reducing power activity was inhibited by $N$. alba extract. It is a source of natural antioxidant and has substantial amount phenols, tannins, and other phytoconstitutents [48].

\section{Anxiolytic activity}

Antidepressant or anxiolytic drugs in use affect the general functioning of the body, and thus researchers are inclined to search similar 
compounds in plants with lesser side effects. N. alba's anxiolytic activity was evaluated by the open field test, light/dark box elevated plus maze test, foot shock induced aggression test, and motor coordination test. The results of the study show that extract of $N$. alba in ethanol was found to have anxiolytic and muscle relaxant properties and has future pharmacological applications [48]

\section{Applications in industry}

Acts as a source of natural gum

P. laevigata is a good source of natural gum. Both In situ and In vivo studies have shown that the plant exudates contain polysaccharides and proteins which make it efficient for gummosis [49]. This property of $P$. laevigata can be explored further to be used in confectionary, sauces, jellies, spray drying of juices, bakery products, adhesives, fixatives, micro encapsulations, wood furniture, gels, cosmetics, and various other industrial uses.

\section{Acts as hyper accumulator of heavy metals}

Phytoremediation is a property of plants to remove contaminants in the environment found mostly near industrial region. Phytoextraction is the form of phytoremediation which involves the eradication of heavy metals by the roots of aerial plants. The effects of cadmium and chromium on shoots and roots of $P$. laevigata plant reflects a reduction in elongation and regulation of growth hormones. The plant is able to germinate properly at different cadmium and chromium concentrations. It thus acts as a hyperaccumulator of cadmium (III) and chromium (VI). In this manner, P. laevigata acts as a purifying agent in the environment near industrial areas [50].

\section{Acts as a source of cultivable endophytic bacteria}

Heavy metalloids contamination causes deterioration of the soil, thus it decreases the microorganisms content, and hence is a serious threat to the health of human beings. The endophytic bacteria are isolated from $P$. laevigata plant. Endophytic bacteria having major activities of xylanase and pectinase are found in this plant. The bacteria having decrease in the physiological production of siderophores and nitrogen fixation are found in abundance in this plant. After isolating endophytes, the root extracts are incubated for protecting against any further microbial contamination and colony counting was done confirming the presence of bacteria [51]

\section{Acts as a food supplement}

$P$. laevigata has been explored as a food source, especially in its native regions where growing other food crops such as wheat and maize is difficult. The dried pods of the plant were converted into flour and were evaluated for its nutritional content. The protein content was found to be similar to cereals and soybean. The plant is also found to be source of fatty and is rich in fiber and ash content. It was also found acceptable to produce ice-creams [15]

\section{CONCLUSION}

Medicinal plants are used as ingredients in various pharmaceutical products since a very long time (Graph 2). Using these plants in drugs and in pharmaceutical industries can serve as a treatment of several diseases. The phytopharmaceutical potentials of P. laevigata, $S$. Cochinchinensis, and N. alba can, therefore, be used in drug design for the treatment of diseases. The most common medicinal properties such as antioxidant, anti-biofilm, and antimicrobial help to eradicate the harmful effects of various microbial and bacterial infections. The cardioprotection potential in P. laevigata can be used in the treatment of heart attacks. These plants also act as a source of food and display several industrial applications such as gum production and use in the preparation of ice-creams. Thus, we conclude by saying that using these unexplored plants can help in the treatment of diseases and a food source as industrial applications.

\section{REFERENCES}

1. Amalraj A, Gopi S. Medicinal properties of Terminalia arjuna (Roxb.) Wight and Arn.: A review. J Tradit Complement Med 2016;7(1):65-78.

2. Carrió E, Vallès J. Ethnobotany of medicinal plants used in Eastern Mallorca (Balearic Islands, Mediterranean Sea). J Ethnopharmacol 2012;141(3):1021-40.

3. Tabuti JR, Lye KA, Dhillion SS. Traditional herbal drugs of Bulamogi, Uganda: Plants, use and administration. J Ethnopharmacol 2003;88(1):19-44.

4. Sharma J, Gairola S, Gaur RD, Painuli RM. The treatment of jaundice with medicinal plants in indigenous communities of the Sub-Himalayan region of Uttarakhand, India. J Ethnopharmacol 2012;143(1):262-91.

5. Petroni LM, Huffman MA, Rodrigues E. Medicinal plants in the diet of woolly spider monkeys (Brachyteles arachnoides, E. Geoffroy, 1806)-a bio-rational for the search of new medicines for human use? Rev Bras Farmacogn 2016;27(2):135-42.

6. Goh MP, Basri AM, Yasin H, Taha H, Ahmad N. Ethnobotanical review and pharmacological properties of selected medicinal plants in Brunei Darussalam: Litsea elliptica, Dillenia suffruticosa, Dillenia excelsa, Aidia racemosa, Vitex pinnata and Senna alata. Asian Pac J Trop Biomed 2017;7(2):173-80.

7. Jena AK, Karan M, Vasisht K. Plant parts substitution based approach as a viable conservation strategy for medicinal plants: A case study of Premna latifolia Roxb. J Ayurveda Integr Med 2017;8(2):1-5.

8. Devi KA, Pandey P, Sharma GD. Plant growth-promoting endophyte Serratia marcescens AL2-16 enhances the growth of Achyranthes aspera L. a medicinal plant. HAYATI J Biosci 2017;23(4):173-80.

9. Chandra S, Chandra D, Barh A, Pankaj, Pandey RK, Sharma IP. Bryophytes: Hoard of remedies, an ethno-medicinal review. J Tradit Complement Med 2016;7(1):94-8.

10. Salem MZM, El-Hefny M, Nasser RA, Ali HM, El-Shanhorey NA, Elansary HO. Medicinal and biological values of Callistemon viminalis extracts: History, current situation and prospects. Asian Pac J Trop Med 2017;10(3):229-37.

11. Torres LG. Use of Prosopis laevigata seed gum and Opuntia ficusindica mucilage for the treatment of municipal wastewaters by coagulation-flocculation. Nat Resour 2012;3(2):35-41.

12. García-andrade M, González-Laredo RF, Rocha-Guzmán NE, Gallegos-infante JA. Mesquite leaves (Prosopis laevigata), a natural resource with antioxidant capacity and cardio protection potential. Ind Crop Prod 2013;44:336-42.

13. Valladares MG. Use of Prosopis laevigata as a corrosion inhibitor for $\mathrm{Al}$ in H2SO4. Int J Electrochem Sci 2013;8:6864-77.

14. Sánchez E, Morales CR, Castillo S, Leos-Rivas C, García-Becerra L, Martínez D, et al. Antibacterial and antibiofilm activity of methanolic plant extracts against nosocomial microorganisms. Evid Based Complent Altern Med 2016;2016: Article ID: 1572697, 1-8.

15. Negrete LO, Morales JA, Garc JC. Effects of increasing amount of dietary Prosopis laevigata pods on performance, meat quality and fatty acid profile in growing lambs. Anim Physiol Anim Nutr 2012;110:1-9.

16. Acharya N, Acharya S, Shah U, Shah R, Hingorani L. A comprehensive analysis on Symplocos racemosa Roxb.: Traditional uses, botany, photochemistry and pharmacological activities. J Ethnopharmacol 2016;181:236-51.

17. Jesurun JR, Jagadeesh S, Ganesan S, Rao V, Eerike M. Antiinflammatory activity of ethanolic extract of Nymphaea alba flower in Swiss albino mice. Int J Med Res Heal Sci 2013;2(3):474-8.

18. Khan N, Sultana S. Inhibition of potassium bromate-induced renal oxidative stress and hyperproliferative response by Nymphaea alba in Wistar rats. J Enzyme Inhib Med Chem 2005;20(3):275-83.

19. Barros AO, Souza RS, Suzany E, Da Costa LM, De Souza TP, De Vasconcellos MC, et al. Antioxidant and hepatoprotective activities of Libidibia ferrea bark and fruit extracts. Int J Pharm Pharm Sci 2014;6(11):71-6.

20. Bhandarkar MR, Khan A. Antihepatotoxic effect of Nymphaea stellata willd. Against carbon tetrachloride-induced hepatic damage in albino rats. J Ethnopharmacol 2004;91(1):61-4.

21. Bakr RO, Wasfi R, Swilam N, Sallam IE. Characterization of the bioactive constituents of Nymphaea alba rhizomes and evaluation of anti-biofilm as well as antioxidant and cytotoxic properties. J Med Plants Res 2016;10(26):390-401.

22. Hesham A, Abdel NB, Jari S, Kalevi P. Hypolipidemic and antioxidant effect of Morus alba L (Egyptian mulberry) root bark fractions supplementation in cholesterol- fed rats. J Ethnopharmacol 2005;78:2724-33. 
23. Flores-Palacios A, Barbosa-Duchateau CL, Valencia-Díaz S, CapistránBarradas A, García-Franco JG. Direct and indirect effects of on Prosopis laevigata in the Chihuahua desert scrubland of San Luis Potosi, Mexico. J Arid Environ 2014;104:88-95.

24. Akhani H. Nature serve. 'Nymphaea alba'. IUCN red list of threatened species. Int Union Conserv Nat 2013;14(1):43-47.

25. Aldrich MV, Gardea-Torresdey JL, Peralta-Videa JR, Parsons JG. Uptake and reduction of $\mathrm{Cr}$ (VI) to $\mathrm{Cr}$ (III) by mesquite (Prosopis spp.): Chromate-plant interaction in hydroponic and solid media studied using XAS. Environ Sci Technol 2004;37(9):1859-64.

26. Kumar KJ, Krishnamurthy G, Kumarn S. Synthesis, characterization, in vitro antimicrobial, anthelmintic and docking studies of new 2- [(e) - \{[4-(1h-1, 2, 4-triazol-1 ylmethyl) phenyl $]$ imino $\}$ methyl $]$ phenol, and their complexes with $3 \mathrm{~d}$ metal ions. Int J Pharm Pharm Sci 2016;8(9):134-9.

27. Lakshmi KS, Vadivu R. Preliminary phytochemical and in-vitro cytotoxic activity of the leaves of Symplocos cochinchinensis (Lour.) S. Moore ssp. Laurina (Symplocaceae). Sch Res Libr 2010;2(2):208-20.

28. Bakr RO, El-Naa MM, Zaghloul SS, Omar MM. Profile of bioactive compounds in Nymphaea alba L. leaves growing in Egypt: Hepatoprotective, antioxidant and anti-inflammatory activity. BMC Complement Altern Med 2013;17:1-13

29. Agarwal H, Gayathri M. Biological synthesis of nanoparticles from medicinal plants and its uses in inhibiting biofilm formation. Asian J Pharm Clin Res 2017;10(5):64-8.

30. De Jesús-Gabino AF, Mendoza-de Gives P, Salinas-Sánchez DO, López-Arellano ME, Liébano-Hernández E, Hernández-Velázquez VM, et al. Anthelmintic effects of Prosopis laevigata n-hexanic extract against Haemonchus contortus in artificially infected gerbils (Meriones unguiculatus). J Helminthol 2010;84(1):71-5

31. López-Aroche U, Salinas-Sánchez D, Mendoza de Gives P, López-Arellano M, Liébano-Hernández E, Valladares-Cisneros G, et al. In vitro nematicidal effects of medicinal plants from the Sierra de Huautla, Biosphere Reserve, Morelos, Mexico against Haemonchus contortus infective larvae. J Helminthol 2008;82(1):25-31.

32. Patankar SB, Mujumdar AM, Sane RT, Remya U. Evaluation of safety profiles of anuradha oil-an herbal wound healing formulation in laboratory animals. Int J Pharm Pharm Sci 2015;7(4):278-82.

33. Sánchez DO, Najera GL, Rivera IL, Ramírez OD, Cisneros MG, García VM. Antimicrobial activity of medicinal plants from the Huautla Sierra biosphere reserve in Morelos (México). Polibotánica 2009:28:213-25.

34. Sunil C, Ignacimuthu S. In vitro and in vivo antioxidant activity of Symplocos cochinchinensis S. Moore leaves containing phenolic compounds. Food Chem Toxicol 2011;49(7):1604-9.

35. Sunil C, Agastian P, Kumarappan C, Ignacimuthu S. In vitro antioxidant, antidiabetic and antilipidemic activities of Symplocos cochinchinensis
(Lour.) S. Moore bark. Food Chem Toxicol 2012;50(5):1547-53

36. Vadivu R, Lakshmi KS. In vitro and in vivo anti-inflammatory activity of leaves of Symplocos cochinchnensis (Lour) Moore ssp Laurina. Bangladesh J Pharmacol 2008;3:121-4.

37. Abbasi MA. Bio Active Chemical Constituents of Symplocos recemosa and Comiphora Mukul. Ph. D. Thesis. Pakistan: University of Karachi; 2004. p. 139

38. Balu S, Alagesaboopathi C. Antivenom activities of some species of andrographis wall. Anc Sci Life 1995;14(3):187-90.

39. Khan MR, Kihara M, Omoloso AD. Antimicrobial activity of Symplocos cochinensis. Fitoterapia 2001;72(7):825-8.

40. Liu P, Liu X. Dynamics of a tumor-immune model considering targeted chemotherapy. Chaos Solitons Fractals 2017;98:7-13.

41. Abida P, Britto AJ, Antoney J, Raj TL. Evaluation of in vitro anticancer activity of Symplocos cochinchinensis (Lour.) S. Moore bark. Int J Herbal Med 2016;4(6):117-9.

42. Koushik OS, Babu PS, Karthikeyan R. In vitro anti-bacterial activity of flowers of Nymphaea alba. Int J Drugs 2015;3(2):47-8

43. Akagi K, Hirose M, Hoshiya T, Mizoguchi Y, Ito N, Shirai T. Modulating effects of ellagic acid, vanillin and quercetin in a rat medium term multi-organ carcinogenesis model. Cancer Lett 1995;94(1):113-21.

44. Recio MC, Rios JL, Villar A. A review of some antimicrobial compounds isolated from medicinal plants reported in the literature 1978-1988. Phytother Res 1989;3(4):117-25.

45. Vajpayee P, Tripathi RD, Rai UN, Ali MB, Singh SN. Chromium (VI) accumulation reduces chlorophyll biosynthesis, nitrate reductase activity and protein content in Nymphaea alba L. Chemosphere 2000;41(7):1075-82.

46. Sharifi N, Souri E, Ziai SA, Amin G, Amanlou M. Discovery of new angiotensin converting enzyme (ACE) inhibitors from medicinal plants to treat hypertension using an in vitro assay. Daru 2013;21(1):74.

47. Bose A, Sahoo M, Ray SD. In vivo evaluation of anti-diarrheal activity of the rhizome of Nymphaea alba (Nymphaeaceae). Orient Pharm Exp Med 2012;12(2):129-34.

48. Afolayan AJ, Jide A, Sharaibi OJ, Kazeem MI. Phytochemical analysis and in vitro antioxidant activity of Nymphaea lotus L. Int J Pharmacol 2013;9(5):297-304.

49. Thippeswamy BS, Mishra B, Veerapur VP, Gupta G. Anxiolytic activity of Nymphaea alba Linn. In mice as experimental models of anxiety. Indian J Pharmacol 2011;43(1):50-5.

50. Buendía-González L, Orozco-Villafuerte J, Cruz-Sosa F, Barrera-Díaz CE, Vernon-Carter EJ. Bioresource technology Prosopis laevigata a potential chromium (VI) and cadmium (II) hyper accumulator desert plant. Bioresour Technol 2010;101(15):5862-7.

51. Román-PonceB, Ramos-Garza J,Vásquez-MurrietaMS, Rivera-OrduñaFN, Chen WF, Yan J, et al. Cultivable endophytic bacteria from heavy metal (loid)-tolerant plants. Arch Microbiol 2010;198(10):941-56. 